\title{
Physical Disability and Femininity: An Intersection of Identities
}

\author{
Xanthe Hunt, Stine Hellum Braathen, and Poul Robleder
}

\section{INTRODUCTION}

Gender, femininity, and masculinity, and what we think about as gender, or womanliness or manliness, and how we feel gendered, or womanly or manly, are subject to substantial social mediation. What that means is that society, the way we are taught from a young age to think about our social world, the media, our schools, and many other social forces, shape how we think about gender, and the characteristics and traits we associate with women (femininity), and men (masculinity).

X. Hunt $(\bowtie)$

Department of Psychology, Faculty of Arts and Social Sciences, Stellenbosch University, Stellenbosch, South Africa

Institute for Life Course Health Research, Department of Global Health, Faculty of Medicine and Health Sciences, Stellenbosch University, Stellenbosch, South Africa

S. H. Braathen

Department of Health Research, SINTEF Digital, Oslo, Norway

e-mail: stine.h.braathen@sintef.no

(C) The Author(s) 2021

X. Hunt et al. (eds.), Physical Disability and Sexuality, https://doi.org/10.1007/978-3-030-55567-2_4 
At the time of writing this book, gender, femininity, and masculinity are highly visible and debated social topics. Not all people fall within the commonly used binary constructs of male/female, and not all people feel comfortable to, or should have to, identify as either man or woman, masculine or feminine; there is a lot in between. Current debates about gender, and the spectrum upon which people may situate themselves, is beyond the scope of this chapter-and (a limitation of this work) all of our participants identified as cisgender, and heterosexual (for definitions of these terms, see our glossary). But what is important to note is that gender, and associated social roles and attributes, are not only personal, and the subject of intense, individual, and diverse experience (as evidenced in current debates), but also subject to a lot of social stuff.

In this chapter we look at the intersection of disability and femininity particularly, and what it means for some of the participants we interviewed. In other sections, we discuss masculinity, but in this chapter, we focus on femininity because this was what our participants who identified as women spoke about. Our goal in this chapter is to examine the ways in which: (a) women with physical disabilities experience their own sense of gender, and femininity; and (b) to bring to light some of the ways in which societal thinking about womanliness and femininity (and here we focus on traditional and dominant ways of thinking about femininity) influence the participants' experiences of themselves.

We will first look at what we mean by gender, and then look at femininity in relation to people born with a physical disability and people who have acquired a physical disability. We discuss some of the stereotypes about disability and femininity - about women with physical disabilities - from previous research, and from our own work, and discuss what such stereotypes might mean for our participants, drawing on their photographs and stories.

\section{Thinking About Gender And Disability}

When we talk about gender, we talk about the state of being a boy/man or girl/woman or neither/both/somewhere in between. Unlike when we talk about a person's sex, gender implies a reference to the social and

P. Rohleder

Department of Psychosocial and Psychoanalytic Studies, University of Essex, Colchester, UK

e-mail: p.rohleder@essex.ac.uk 
cultural differences between the categories "boy/man and girl/woman" rather than biological differences. Gender refers to our sense of self and not our anatomy. Our gender reflects the social and cultural constructions of sex with which we choose to identify: masculinity or femininity, or a bit of both or neither. Sex (what we might be defined as based on our anatomy) does not necessarily correspond to gender: people who are cisgender might have male sex organs, identify as men, and feel masculine; people who are transgender, though, may have female sex organs, identify as men, and feel masculine too.

Masculinity and femininity are not neutral concepts-they are ideologically, politically, culturally, and emotionally loaded, as evidenced in current debates around transgender people, and historical (and ongoing) challenges facing LGBTQ+ people. It is beyond the scope of this chapter to examine the myriad ways in which societies, regimes, and other social structures and groups may construct and contest these constructs.

In this chapter, though, we have to define femininity. Here we choose a simple one: qualities or attributes regarded as characteristic of people who identify as women. This is nice and broad, and it specifies the scope of the data we discuss here: any information concerning experiences of or opinions about, the qualities or attributes identified with woman-ness.

Now, a quick Google search brings up words such as "womanhood", "female gender role", "feminine traits" (understanding, empathetic, sensitive, submissive, gentle, modest, willowy, and pretty), "attributes and characteristics traditionally associated with girls and women", if you search femininity.

The first question we must consider, then, is what people have said and written in the past, about disability in relation to these characteristics: what does it mean for physical disability to be feminine, or feminineness to be embodied by someone with a physical disability?

Usually, gender is one of the primary markers of identity-for reasons social and political, we are most likely to identify people as male or female or identify them by ethnicity, age, occupation, class, or nationality (note, here, that we identify them, usually, as being cisgender, that is, assuming that what we see-physical sex-bears a direct relationship to the gender identity we assume them to have, although this is not necessarily the case) (Rich, 2014).

Unlike the case of the majority without disability, however, past research and theory suggest that, for people with a disability, it is their disability that is the primary hallmark of identity. That is, it is an identity which supersedes gender (Goffman, 1963; Rich, 2014). One is a person with a physical disability first, and a woman or man second. This is 
not necessarily how the person with disability identifies themselves, but, rather, the way in which society identifies them.

In the sections to follow, we will explore whether, and how, this ranking of identity might be the case, and what it means for women with physical disabilities. Turning our attention first to the meeting between physical disability and femininity, we discuss how authors have proposed femaleness to be variously accentuated or negated by physical impairments. We then take a look at some of the research which has tried to unpack the intersection of femininity and disability as it impacts on the lived experience of women with physical disabilities. First of all, however, it is necessary to examine the manner in which gender identity development (the process of coming to identify as female or feminine) as a woman with a physical disability differs depending on whether one's physical impairment is something with which one is born (congenital) or acquired.

\section{Femininity and Sexuality in the Context of Acquired vs Congenital Physical Disability}

When a woman's physical disability is acquired, particularly in mid- or late-life, then her gender and sexual identity development has already occurred: she may have already pursued sexual relationships, experienced intimacy, and developed a sense of herself as a woman (Higgins, 2010). The development of one's sexual self and sense of oneself as a gendered being for women with congenital disabilities, however, occurs in the context of disability. Relationships, sex, intimacy, and ideas about gender roles must all be explored in the context of a physical impairment, and a society which is not always kind in its reactions to it (MacDougall \& Morin, 1979).

We heard the example in the chapter before, about the transitions which women go through when they acquire a physical disability later in life. Research suggests that some women with congenital physical disabilities are limited in their expression of their sexuality (not that they limit themselves, but that society might limit them) (Howland \& Rintala, 2001; Vaughn, Silver, Murphy, Ashbaugh, \& Hoffman, 2015). To nuance this statement: what has been found is that Howland and Rintala (2001) found that some women with physical disabilities delayed dating because they had been raised with the assumption that their disability somehow excluded them from sexual life. Other women in their study felt that they lacked the age-appropriate socialisation experience to date, because as 
young people, they had been sheltered by their parents, and social exclusions due to their impairment. This indicates that when sexual and gender identity development occurs in the context of disability (as opposed to before its onset), the result can be inhibitory on sexual development and trouble women's sense of themselves as feminine ( $\mathrm{Li} \& \mathrm{Yau}, 2006$; MacDougall \& Morin, 1979). This makes sense if we consider how sexual and gender identity development takes place. As we grow up, we are slowly but surely given feedback from our social environment concerning appropriate behaviour for our gender, and how we are measuring up to societies' ideas about our fitness as members of our sex, and as people performing our gender. We are given gender models against which to measure ourselves (from Fairy tale characters to celebrities), and we are subject to social feedback which tells us whether we are appropriately performing desirability as is fitting of the gender with which we identify. When one is subject to an identity marker such as disability (an identity marker which may even trump the markings of gender), then this feedback loop is interrupted or perverted, and gender identity development is thrown into flux.

Firstly, there is an absence of visible prototypes of femininity for young girls with disabilities, and-as society tells these girls that they are not like people without disability - icons without disability may seem to have little relevance for them. Secondly, the kinds of social feedback which they may receive concerning their suitability as a feminine female sexual subject, may be negative. Taken together, these forces may mean that making sense of where one fits in terms of femaleness and femininity, is no mean feat for girls growing up with physical disabilities.

This can be exemplified by Pride's story. Pride suffered from polio as a small child, resulting in one of her legs being formed differently to the other, which causes her a lot of pain, and she walks with a limp. Throughout her life she had heard many myths and rumours spoken about her behind her back. The rumours included ones that she could not have sex, not have a child, and therefore she was not suitable as a girlfriend, and could not get married. As a young girl in primary school she recalls her friends telling her that because of her disability, "you can't have a boyfriend, you can't get a child, you can't get married". Today, as an adult, she believes that they were ignorant, and not aware of the realities of her disability: 
They don't know. They don't know. But I also wanted to be loved, to belong, to be appreciated. But people couldn't understand. I remember, the first time I was at high school now, and then the boys would follow me. And then I was with this boy, and this boy heard that thing about me, and then the other one would pass and say, oh, I don't think that disabled people can have boyfriends. But that would come to my heart also.

Most boys and men in her youth would not pay attention to her, but one particular boy liked her:

With this one, I don't know what happened. He was just interested in me, and talking. And when you talk the person will realise, no, man, this person is normal, the way she talks and the way she does things. No, she's normal, there's nothing wrong... For me it was important because at least there was someone who could understand that I'm also human. I also have feelings like other people... My friends (had boyfriends) long time before me. So for them it was easy to have boyfriends, but for me it was not easy because nobody wants to have a girlfriend who looks like this.

She has been in a few relationships in her life, and has never felt that her partners have seen or treated her differently because of her disability. The problems, she explains, only ever arise from people without disability outside of the relationship:

The people who are letting me down are the people outside the relationship who would say those things. Oh, you are in a relationship with a person like this? You know, people can talk and gossip about all those things. How can you have a relationship with someone like this? How are you going to do this and that? But in a relationship, no, I never experienced that because of my disability.

When disability is acquired, gender identity may be thrown into flux, but in different ways: women may measure themselves against past versions of themselves, and feel less feminine or less desirable; gender roles such as motherhood, which they previously felt attainable to them, they may suddenly question. However, research suggests that, for women with acquired physical disabilities, gender identity and sexual self-esteem is more established than for women with congenital disabilities (Howland \& Rintala, 2001). Though by no means the final word on experiences of gender in the context of congenital or acquired disability, what this section is intended to do is provide a backdrop against which the 
following discussion can be considered. In some cases, we will see how acquired disability is negotiated in the context of an already flourishing sense of feminine self. In other sections, we will consider what it means to nurture ones' sense of self as feminine in the developmental context of physical disability. In answering these questions, it is important to think about what physical "difference" ${ }^{1}$ means for femininity in the broadest sense, before refining its implications for the sexual and gender identity development of individual women.

\section{Gender Ideologies and Physical Disability: More or Less a Woman?}

Work on the relationship between disability and gender has historically been limited, partly due to the fact that people with disabilities are taken as being asexual, or sometimes even as a third gender (Shakespeare, 1994, 1999). Yet, for the past 20 years, a substantial body of work has used gender as a lens through which to explore disability (Lashley, 2016; Moodley \& Graham, 2015; Rodarte \& Muñoz, 2004), including important work in South Africa (Chappell, 2015, 2017; van der Heijden, Abrahams, \& Harries, 2019). In the past it was argued that women with physical disabilities were doubly feminised (Rich, 2014). That is, women are traditionally stereotyped as weaker and more passive than men, and weakness and passivity are ascribed to people with physical disabilities, and so women with physical disabilities are simply twice as female. However, various authors (Cheng, 2009; Rich, 2014; Schlesinger, 1996; Tilley, Walmsley, Earle, \& Atkinson, 2012) have argued against this "logic" that, actually, most evidence suggests that disability disrupts traditional ideologies and social norms regarding female gender identity and femininity just as much as male gender identity and masculinity. Consider the idea (be it right or wrong) that women should be able to cook and clean and look after their domestic space. For a woman with a severe spinal cord injury, this might not be possible. Because of this disruption, common myths relating to the gender, and associated traits and roles, of people with physical disabilities are constructed in opposition

\footnotetext{
${ }^{1}$ Different, here, is in inverted commas because we do not mean that people with physical disabilities are different-different from what? What we want to show, however, is that, in a society which sees being without disability as the norm, people with physical disabilities are seen as different.
} 
to the traditional gender characteristics of their respective group, should they identify with one (Schlesinger, 1996; Tilley et al., 2012). In the case of women with physical disabilities, myths concerning their sexuality and gender include that they are asexual, unmarriageable, infantile, cannot be mothers, are passive, and are a burden to carers and partners (Anderson \& Kitchin, 2000; Galvin, 2005; Hassouneh-Phillips \& McNeff, 2005; Hunt, Swartz, Rohleder, Carew, \& Hellum Braathen, 2018). We saw, in Pride's story presented above, how others' attitudes in this area influenced her experience of herself.

Work concerning gender stereotypes and disability has supported the idea that disability negates femininity rather than boys it. In a large study on disability stereotypes (Nario-Redmond, 2010), the researchers asked students to describe men and women with disabilities. The idea was that the students' short descriptions would tell the researchers something about stereotypes regarding disability and gender. They did. The researchers then contrasted these stereotypes with stereotypes regarding men and women without disability. Only women and men without disability were stereotyped along traditional gender lines, whereas persons with disabilities were characterised as asexual and unattractive. Traditional female gender stereotypes were only found for targets without disability, and the stereotypes of female targets with disabilities were characterised as more similar to stereotypes for male people with disabilities. Overall, the stereotypes for women with disabilities were, well, less gendered. In a paper the editors of this book wrote concerning people without disability's stereotyping of people with physical disabilities, we found a similar disjuncture (Hunt et al., 2018): the findings suggested that stereotypes of people with physical disabilities were undifferentiated by gender. So, where people without disability would associate "traditional" characteristics with men and women without disability, and these characteristics would be very different for men and for women, when people without disability associated traits with people with physical disabilities, the traits for men with physical disabilities and women with physical disabilities were very similar, and foregrounded disability (Hunt et al., 2018).

\section{The Effects on Women}

An important theoretical note which must be made at this point is one concerning a way of thinking about social forces called symbolic interactionism (Rose, 1962). Symbolic interaction theory examines the ways 
in which "societal norms, stereotypes, and judgments affect stigmatized groups such as persons with physical disabilities" (Rich, 2014, p. 419). That is, it strives to allow us to think about how the way in which people "out there" in society think about us, influences the world "in here", in our minds. This theory is particularly concerned with how stigmatised groups may come to internalise negative stereotypes about themselves: if everyone thinks we are like this, then maybe we are like this?

Femininity is as much shaped by how women who identify as feminine feel about and see themselves, as it is about how others see them. For any girl or woman, coming to terms with and embracing womanhood, femininity, and sexuality, or not, is a process that we live with and experience throughout our lives. For women whose bodies deviate from the norm this process is likely more complicated and challenging. Amongst the women that we interviewed, several explained that multiple events in their lives over long periods of time had changed the way they thought of themselves, both negatively and positively. This was also something one of the participants with a congenital physical disability in our study spoke about. Throughout her life she had been told that she was not a "proper woman", that she was not suitable as a romantic partner, wife, and mother:

...the world or others, this is what they see when they see me, and it's not an option, but literally that I'm not an option.

Eventually she had also come to believe this herself, internalising the views of the "outside world". As a result she did not recognise it if someone showed a romantic interest in her, believing it not to be possible:

I didn't see it. I can't say it wasn't there. I didn't see it. I mean, now with the benefit of hindsight, I think maybe it was sometimes there but that I was trained to block it out and that I definitely didn't encourage it, and that's what I'm sorry about.

Gender is enacted through the performance of certain activities, activities which disability may make difficult or impossible (either in reality, or in the eyes of others). Symbolic interactionists have also suggested that marginalised groups of persons employ a variety of strategies to manage other people's perceptions of them (Goffman, 1963; Rich, 2014). According to this perspective, compensation strategies are undertaken by individuals in order to hide, minimise, compensate for, or negate the 
socially stigmatised elements of their identities. When disability does meet gender, then, the former often works to negate the latter, in interactionist terms. In such a context-where women with physical disabilities are constantly butting up against others' preconceived ideas about their gender, femininity, and identity, their abilities, and capabilities-how do they enact or claim gender?

Both Khadija and Cleone indicated their long hair as an important symbol of their femininity, making them attractive to men and defining them as women in the way that they wanted to be womanly. The long hair was, for them, a way to compensate for their sense of otherwise lacking some socially defined aspects of femininity. Khadija had taken a picture of her long hair to illustrate her femininity. She explained the picture in the following way (Image 4.1).

So I was told that your hair is your beauty and, if you die, it covers you. So I'm trying to illustrate the importance for me of wearing a scarf and being dressed in a certain way. But other than that, that's all that I'm holding

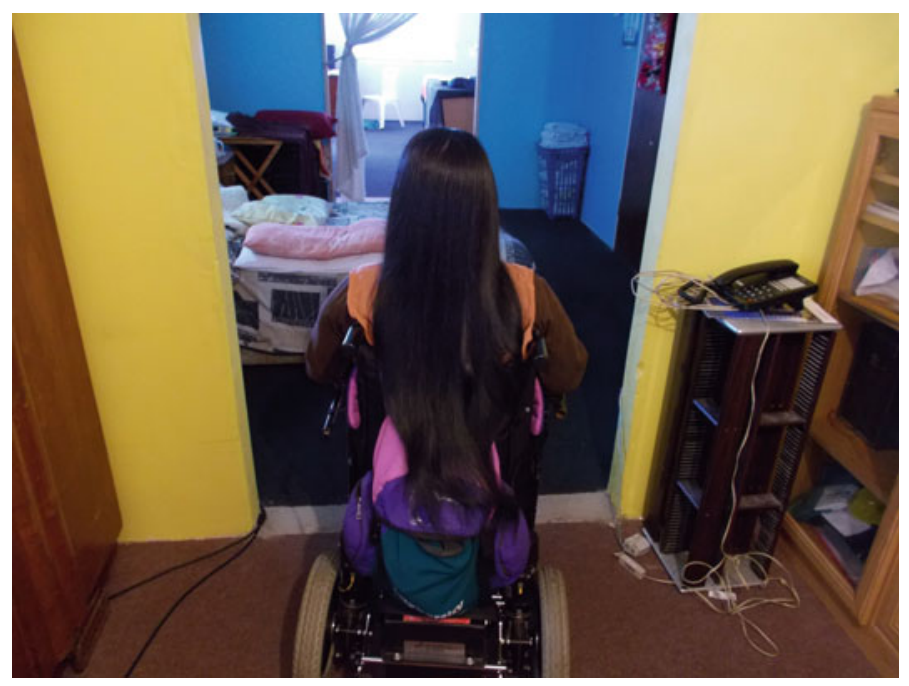

Image 4.1 Khadija is pictured, back to the camera, with her long hair hanging down over her shoulders and the back of her wheelchair (Photo by supplied by Khadija, photographer not recalled) 
onto, it's my beautiful long hair. It still makes me feel that I'm a woman. My hair is part of my womanhood. (Khadija)

Similarly, Cleone said the following of the importance of her long her to shaping her femininity and attractiveness:

So it was one of the most fascinating evenings for me because I had two guys come onto me in the same evening and it was such a boost to my ego. I really didn't feel like going. I didn't make any effort to make myself look good, but I had really beautiful, long hair. I must show you the picture, very nice, long hair. And I do think that that is the... what is the word...the appeal and attraction to men because of the hair.

Noluthando felt that her good looks were an important factor in determining her femininity and defining herself as a person, as a woman, and as a sexual being. Noluthando acquired a physical disability after a car accident in her twenties. She had worked as a model before the accident, and her good looks and keeping a neat and flawless appearance had always been important to her. When she was injured in the accident she needed to use a wheelchair, and, according to her account, her appearance changed. Noluthando explained why it is perhaps more important for her to look beautiful after acquiring a disability:

I said I want to be even more (beautiful) than at the time when I was walking. I want to be a model on this wheelchair. So that's what I told myself. That's why I can't stop to be that model that I've been before. I'm telling myself even today that I'm still a model. And when people look at me they must see that, really, this lady is a model. And I must look beautiful always. It doesn't matter if I sit in a wheelchair, but I must look good. People must know that it's not only people who are able-bodied who can look good. Also us, we are differently-abled, but we need to look good. We need to take care of ourselves.

We know that gender roles and norms affect the embodied sexuality of women with physical disabilities. Specific activities are required of people in order to claim a gender role (Paludi, 2010). Many women with physical disabilities are excluded, or are perceived to be excluded, from such activities (remember the woman with the spinal cord injury who may not be able to cook and clean and run after children). This may mean that, for 
women with physical disabilities, womanhood—and a female gender identity-are achieved statuses: one must prove, more than women without disability, that one is capable of performing femaleness or femininity (Dotson, Stinson, \& Christian, 2003). This is particularly difficult in light of societal ideas about what it means to be female or feminine. Take, for instance, appearance. Women in general are affected by societal expectations regarding their physical size, shape, and gracefulness (Wolf, 1991). As women with physical disabilities have bodies which differ from the prescribed ideal, they are vulnerable to negative appraisal; both their own, and others' (Paludi, 2010; Wendell, 2006).

Women with physical disabilities may experience their bodies as deficient in relation to conceptions of the ideal body, and thus flawed (Peuravaara, 2013). Researchers in England found that women with physical disabilities enacted exaggerated gender performances in order to affirm their gender identity (Batty, McGrath, \& Reavey, 2014). Participants in these researchers' study gave accounts of performing hyperfeminine roles in order to compensate for the fact that others might see them as asexual, as well as their own sense of having their gender called into question. Thus, compensating for the "loss", or altering, of one's original sense of gender identity and femininity following an acquired impairment, or developing an exaggerated way of performing one's gender identity in the presence of a congenital disability, maybe common strategies employed by women with physical disabilities to combat the degendering that their disability may be the subject of by society (there is also evidence that this occurs amongst men with physical disabilities, as you will see in Chapter 6). Women with physical disabilities may, equally, try to hide their impairments in an attempt to cover up the visible signs of disability which could mark them as less feminine (Batty et al., 2014; Li \& Yau, 2006). We also know that physical disability impacts on women's ideas about how able they are to perform desired gender roles. As the author Malacrida (2009) notes,

Women are expected to aspire to norms of femininity that include ideal motherhood, where mothers are positioned as ever available, ever nurturing providers of active, involved and expert mothering - indeed, being a caregiver is a master status for adult women in modernity.

For instance, women with acquired physical disabilities in adulthood may feel that their motherhood role in the family is totally lost, and that 
they will never be able to have children ( $\mathrm{Li} \&$ Yau, 2006). Women with congenital physical disabilities may believe that this role will never be theirs. Unfortunately, research suggests that due to internalised doubts regarding their physicality and femininity, women with physical disabilities may feel that success in relationships or marriages bolsters their normalness and femaleness, whilst failed relationships reinforce perceptions of them as asexual (Galvin, 2005). This can put them at risk of staying in abusive or otherwise damaging relationships (Kvam \& Braathen, 2008).

As is apparent, when femininity and disability meet, the interaction of identities is complex. Theory, and some research, suggests that disability works to trouble and at times negate not only society's views of women with physical disabilities as "adequately feminine", but also women with physical disabilities' sense of themselves as feminine beings. However, we must remember that masculinity and femininity are highly cultural, contextual, and even individual concepts, and are thus in constant flux, and so one must be careful not to make assumptions about the experiences of individual men and women.

In the chapter which follows, one of the participants in the study, who has gone on to co-author academic articles with the research team, provides some personal reflections on one experience of femininity in the context of a physical disability which is as moving as it is informative.

\section{Concluding Notes and Take-Home Points}

What is needed to change things? Some of the experiences outlined by the women who shared their stories in their chapter were difficult: they felt uncomfortable in their sense of themselves, and they felt that they did not "measure up" as women. Over time, happily, this shifted for some of them, and they shared experiences, too, of feeling womanly, beautiful, powerful, and of having loving relationships. Still, their accounts foreground some of the difficulties which face young women with disabilities, and women who acquire disabilities in the course of their lives: What can be done to make things better for these women? To make feeling feminine as a woman with a physical disability a non-issue? To make young people with disabilities who want to feel feminine, regardless of sex, able to do so without society telling them otherwise?

We would suggest it is a matter of representation and attitude change: central to most of the women's stories, here, was the sense that as people without disabilities themselves (prior to acquiring a disability), or from 
people without disabilities who they encountered (as people with disabilities), disability is framed as "less than" non-disability, and femininity is normatively embodied is "better than" femininity which is embodied in a person with a physical disability. For both of these things to change, social representations of femininity-in movies, magazines, the movies, textbooks, sexual education curricula, music videos, and elsewhere-need to include women with physical disabilities. Equally, social representations of physical disability - in movies, magazines, the movies, textbooks, sexual education curricula, music videos and elsewhere-need to be more, and include people with physical disabilities embodying a range of gender identifies, in a range of ways, with social value.

Attitude change is more complicated, because although it may happen inevitably as a result of more representational diversity, it also may not. Attitude change is complicated and poorly understood: if we as societies were any good at changing attitudes, racism, sexism, homophobia, transphobia, and other common forms of prejudice would not be as common as they are. However, awareness-raising and education around broader and inclusive conceptions of sexuality itself are needed. Contact between people without disability and people with disabilities, and inclusion of people with disabilities, in every sphere of life needs to be foregrounded. Research and writing such as this, and products from this project and those much bigger and diverse than this one, need to be shared and engaged with. If dialogue drives awareness, and awareness may lead to attitude change, then content to spark dialogue is needed.

\section{REFERENCES}

Anderson, P., \& Kitchin, R. (2000). Disability, space and sexuality: Access to family planning servicesl. Social Science and Medicine, 51(8), 1163-1173.

Batty, R., McGrath, L., \& Reavey, P. (2014). Embodying limb absence in the negotiation of sexual intimacy. Sexualities, 17(5-6), 686-706.

Chappell, P. (2015). Queering the social emergence of disabled sexual identities: Linking queer theory with disability studies in the South African context. Agenda, 29(1), 54-62.

Chappell, P. (2017). Dangerous girls and cheating boys: Zulu-speaking disabled young peoples' constructs of heterosexual relationships in Kwazulu-Natal, South Africa. Culture, Health \& Sexuality, 19(5), 587-600. 
Cheng, R. P. (2009). Sociological theories of disability, gender, and sexuality: A review of the literature. Journal of Human Behavior in the Social Environment, $19(1), 112-122$.

Dotson, L. A., Stinson, J., \& Christian, L. (2003). People tell me I can't have sex: Women with disabilities share their personal perspectives on health care, sexuality, and reproductive rights. Women \& Therapy, 26(3-4), 195-209.

Galvin, R. D. (2005). Researching the disabled identity: Contextualising the identity transformations which accompany the onset of impairment. Sociology of Health of Illness, 27(3), 393-413.

Goffman, E. (1963). Stigma: Notes on a spoiled identity. Garden City, NY: Jenkins, JH \& Carpenter.

Hassouneh-Phillips, D., \& McNeff, E. (2005). "I thought i was less worthy": Low sexual and body esteem and increased vulnerability to intimate partner abuse in women with physical disabilities. Sexuality and Disability, 23(4), 227.

Higgins, D. (2010). Sexuality, human rights and safety for people with disabilities: The challenge of intersecting identities. Sexual and Relationship Therapy, 25(3), 245-257.

Howland, C. A., \& Rintala, D. H. (2001). Dating behaviors of women with physical disabilities. Sexuality and Disability, 19(1), 41-70.

Hunt, X., Swartz, L., Rohleder, P., Carew, M., \& Hellum Braathen, S. (2018). Withdrawn, strong, kind, but de-gendered: Non-disabled South Africans' stereotypes concerning persons with physical disabilities. Disability \& Society, 33(10), 1579-1600. https://doi.org/10.1080/09687599.2018.1498768.

Kvam, M. H., \& Braathen, S. H. (2008). "I thought... maybe this is my chance" sexual abuse against girls and women with disabilities in malawi. Sexual Abuse, 20(1), 5-24.

Lashley, K. A. (2016). Girls on fire: Gender and disability in "The Hunger Games" and "Divergent". Doctoral dissertation, Morgan State University.

Li, C. M.-N., \& Yau, M. K.-S. (2006). Sexual issues and concerns: Tales of Chinese women with spinal cord impairments. Sexuality and Disability, 24(1), $1-26$.

MacDougall, J., \& Morin, S. (1979). Sexual attitudes and self-reported behavior of congenitally disabled adults. Canadian Journal of Behavioural Science/Revue Canadienne Des Sciences Du Comportement, 11(3), 189.

Malacrida, C. (2009). Performing motherhood in a disablist world: Dilemmas of motherhood, femininity and disability. International Journal of Qualitative Studies in Education, 22(1), 99-117.

Moodley, J., \& Graham, L. (2015). The importance of intersectionality in disability and gender studies. Agenda, 29(2), 24-33.

Nario-Redmond, M. R. (2010). Cultural stereotypes of disabled and nondisabled men and women: Consensus for global category representations and diagnostic domains. British Journal of Social Psychology, 49(3), 471-488. 
Paludi, M. A. (2010). Feminism and women's rights worldwide. Barbara, CA, US: ABC-CLIO.

Peuravaara, K. (2013). Theorizing the body: Conceptions of disability, gender and normality. Disability o Society, 28(3), 408-417.

Rich, K. (2014). "My body came between us" accounts of partner-abused women with physical disabilities. Affilia, 29(4), 418-433.

Rodarte, I. T., \& Muñoz, M. P. B. (2004). Inventory of sexual experiences and response in disability (IEReSDi): Construction and validation of the scale of the sexual response in people with disabilities. Sexuality and Disability, 22(3), $181-195$.

Rose, A. M. (1962). A systematic summary of symbolic interaction theory. Human Behavior and Social Processes: An Interactionist Approach, 3-19.

Schlesinger, L. (1996). Chronic pain, intimacy, and sexuality: A qualitative study of women who live with pain. Journal of Sex Research, 33(3), 249-256.

Shakespeare, T. (1994). Cultural representation of disabled people: Dustbins for disavowal? Disability \& Society, 9(3), 283-299.

Shakespeare, T. (1999). The sexual politics of disabled masculinity. Sexuality and Disability, 17(1), 53-64.

Tilley, E., Walmsley, J., Earle, S., \& Atkinson, D. (2012). 'The silence is roaring': Sterilization, reproductive rights and women with intellectual disabilities. Disability \& Society, 27(3), 413-426.

van der Heijden, I., Abrahams, N., \& Harries, J. (2019). Additional layers of violence: The intersections of gender and disability in the violence experiences of women with physical disabilities in South Africa. Journal of Interpersonal Violence, 34(4), 826-847.

Vaughn, M., Silver, K., Murphy, S., Ashbaugh, R., \& Hoffman, A. (2015). Women with disabilities discuss sexuality in San Francisco focus groups. Sexuality and Disability, 33(1), 19-46.

Wendell, S. (2006). Toward a feminist theory of disability. In L. J. Davis (Ed.), The disability studies reader (pp. 243-256). New York and London: Taylor \& Francis.

Wolf, N. (1991). The beauty myth: How images of beauty are used against women. New York: William Morrow and Company Inc. 
Open Access This chapter is licensed under the terms of the Creative Commons Attribution 4.0 International License (http://creativecommons.org/licenses/ by $/ 4.0 /$ ), which permits use, sharing, adaptation, distribution and reproduction in any medium or format, as long as you give appropriate credit to the original author(s) and the source, provide a link to the Creative Commons license and indicate if changes were made.

The images or other third party material in this chapter are included in the chapter's Creative Commons license, unless indicated otherwise in a credit line to the material. If material is not included in the chapter's Creative Commons license and your intended use is not permitted by statutory regulation or exceeds the permitted use, you will need to obtain permission directly from the copyright holder.

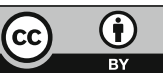

